\title{
Millimeter Wave on Chip Antenna Using Dogbone Shape Artificial Magnetic Conductor
}

\author{
Guo Qing Luo, Zheng Zheng Song, Xiao Hong Zhang, and Xiao Ping Hu \\ The Key Laboratory of RF Circuits and System of Ministry of Education, Hangzhou Dianzi University, Hangzhou 310018, China \\ Correspondence should be addressed to Guo Qing Luo; gqluo@emfield.org
}

Received 6 September 2013; Accepted 28 September 2013

Academic Editor: Yu Jian Cheng

Copyright (C) 2013 Guo Qing Luo et al. This is an open access article distributed under the Creative Commons Attribution License, which permits unrestricted use, distribution, and reproduction in any medium, provided the original work is properly cited.

\begin{abstract}
An artificial magnetic conductor (AMC) applied in millimeter wave on chip antenna design based on a standard $0.18 \mu \mathrm{m}$ CMOS technology is studied. The AMC consisting of two-dimensional periodic dogbone shape elements is constructed at one metal layer of the CMOS structure. After its performance has been completely investigated, it has been used in an on chip dipole antenna design as an artificial background to enhance efficiency of the dipole antenna. The result shows that $0.72 \mathrm{~dB}$ gain has been achieved at $75 \mathrm{GHz}$ when the AMC is constructed by a $4 * 6$ dogbone array.
\end{abstract}

\section{Introduction}

In recent years, applications of millimeter-wave systems have great significance in communications, radar, guidance system, remote sensing technology, radio astronomy, and so on. Millimeter-wave band is defined as a spectrum from $30 \mathrm{GHz}$ to $300 \mathrm{GHz}$, whose corresponding wavelength is from $10 \mathrm{~mm}$ to $1 \mathrm{~mm}$. Millimeter-wave system researches were firstly started in the United States, Japan, Europe, and other advanced countries. In the past, millimeter-wave systems were used in the military and the scientific community. Now, they are widely used in commercial applications, such as automotive collision avoidance radar, local multipoint distribution services (LMDS), and local area networks (WLANs) [1-4]. Because of the short wave length in millimeter-wave band, millimeter-wave devices have small size, strong antiinterference, and other advantages.

Reflector antennas, horn antennas and lens antennas, are typically used for millimeter-wave antenna of the radio system [5-7]. Reflector antenna and horn antenna are mechanical structures and occupy large volumes. With the development of wireless communication and semiconductor technology, antenna on chip (AoC) was presented to meet the requirement of high integration and compact size. In this paper, a standard $0.18 \mu \mathrm{m}$ CMOS technology with six metal layers is used in AoC design. In order to avoid the low radiation efficiency, the bottom metal layer cannot be used as the shield between the silicon dioxide layer and the silicon substrate. But most of the power will be dissipated in the silicon substrate as heat for its low resistivity and high permittivity. For instance, a $140 \mathrm{GHz}$ on chip antenna implemented in $65 \mathrm{~nm}$ CMOS process by [8] has a gain of only $-25 \mathrm{~dB}$. Therefore, gain enhanced methods of AoC should be investigated.

Artificial magnetic conductor (AMC) inserted between antenna and the silicon substrate is presented in [9-12]. AMC can be adopted to redirect one-half of the radiation back to the opposite direction so that antenna gain can be enhanced to some extent. In this paper, an AMC composed of periodic dogbone shape conductors above a ground plane is placed underneath a dipole to improve the proposed on chip antenna performance.

\section{Dogbone Shape AMC}

The dogbone shape AMC, as a sort of the texture presented in [13], provides a good shielding and reflecting capability. Its shape and dimension are shown in Figure 1. Its equivalent circuit model provides an approximate method to calculate the magnetic resonant frequency of a ground-backed dogbone element. According to the equations, we can easily 


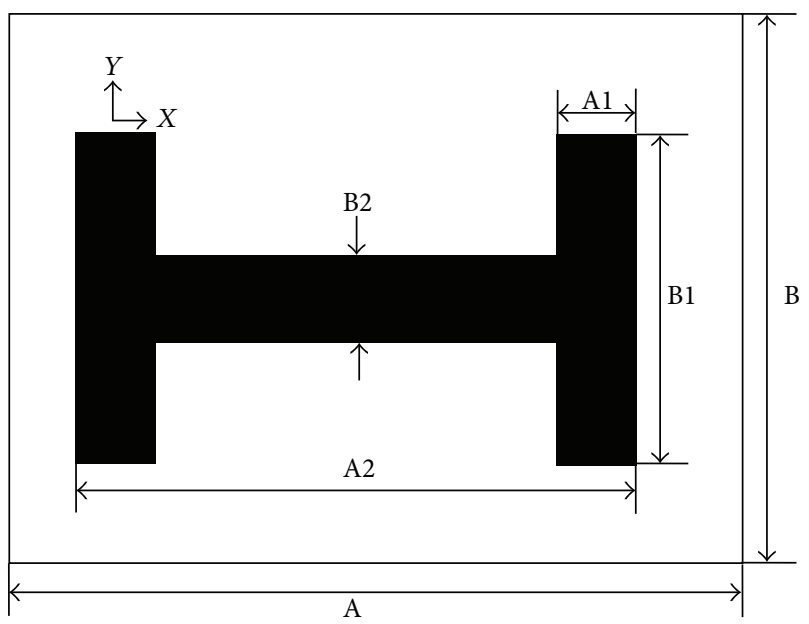

FIGURE 1: Geometrical configuration of a dogbone shape element.

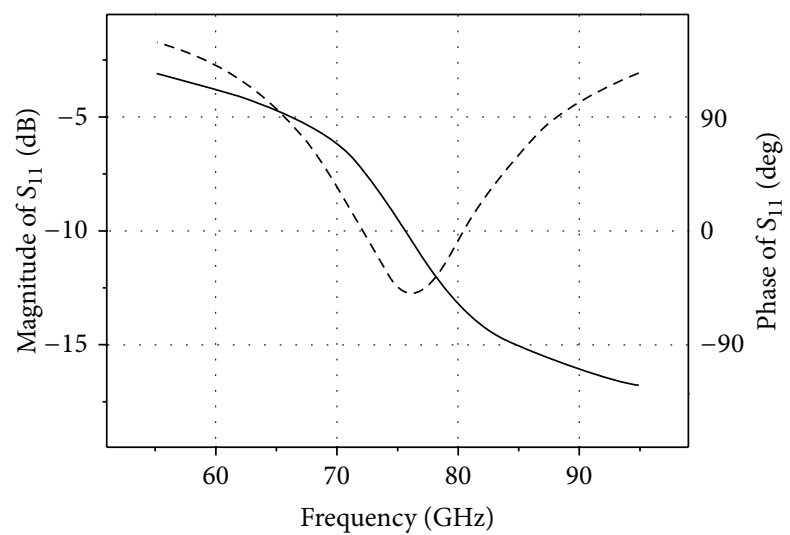

- Magnitude

- - Phase

Figure 2: Magnitude and phase of reflection coefficient of the dogbone shape AMC.

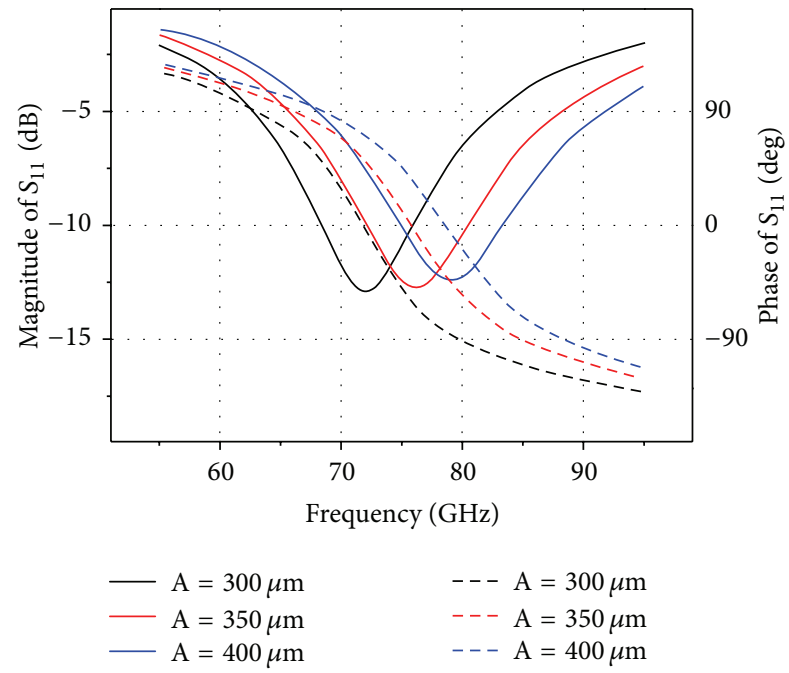

FIGURE 3: Magnitude and phase of reflection coefficient versus geometrical parameter A of the proposed AMC.

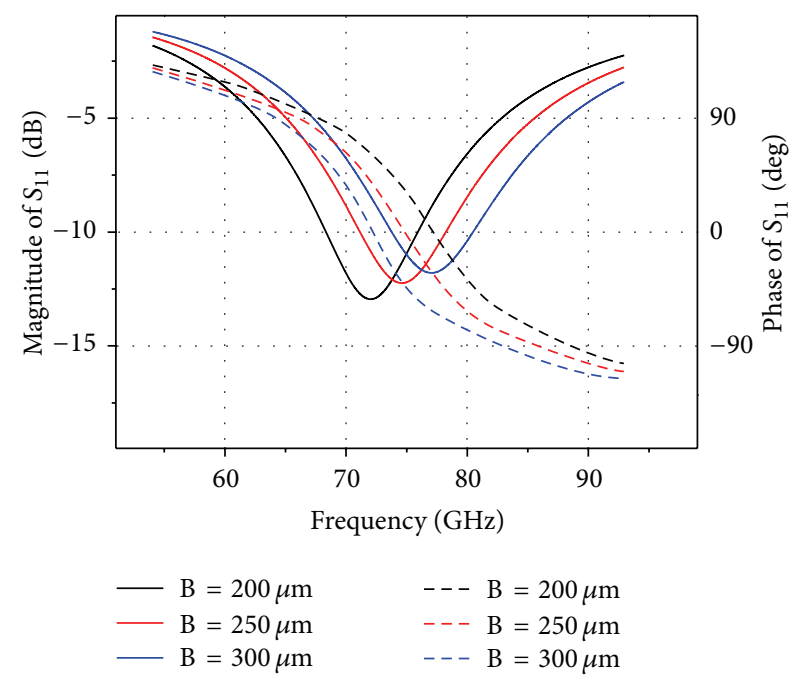

FIgURE 4: Magnitude and phase of reflection coefficient versus geometrical parameter B.

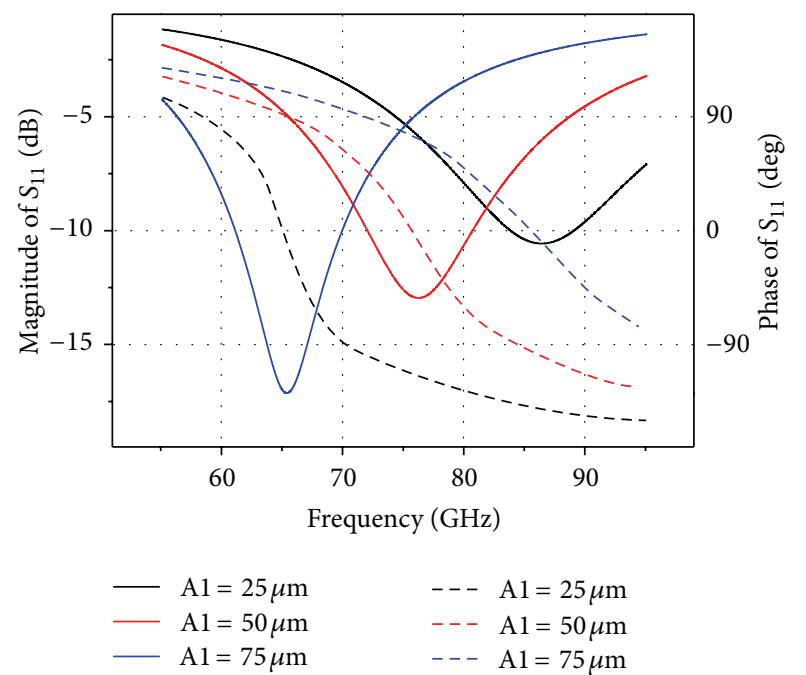

FIGURE 5: Magnitude and phase of reflection coefficient versus geometrical parameter A1.

get geometrical parameters of a dogbone element whose resonant frequency is $75 \mathrm{GHz}$.

A simulation setup of plane wave incidence on an AMC made by a periodic array of ground-backed dogbone unit cell with geometrical parameters of $\mathrm{A}=350, \mathrm{~B}=\mathrm{A} 2=$ $250, \mathrm{C}=\mathrm{B} 1=150, \mathrm{~B} 2=20$, and $\mathrm{A} 1=50$ (unit: $\mu \mathrm{m}$ ) has been done. Periodic boundary conditions are applied in the simulation. The magnitude and phase of the plane wave reflection coefficient are shown in Figure 2. From the figure, it can be found that the proposed structure acts as AMC within a frequency range $\left(-90^{\circ}<\right.$ phase $\left.<90^{\circ}\right)$ from 67 to $83 \mathrm{GHz}$. Frequency responses of the proposed AMC varied with different geometrical parameters are shown in Figures $3,4,5,6,7$, and 8 . The proposed AMC operating frequency is mainly determined by the geometrical parameters of A1, A2, 


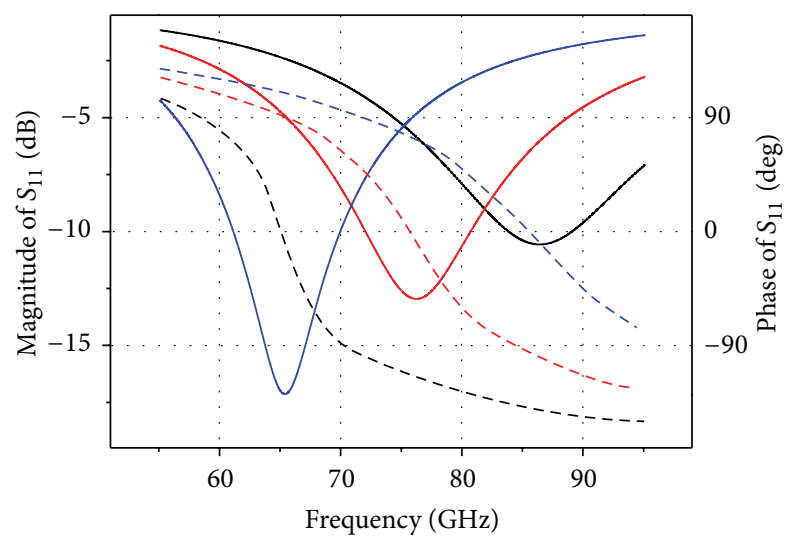

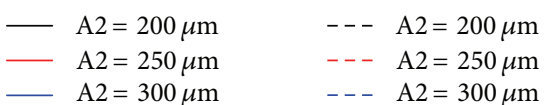

FIgURE 6: Magnitude and phase of reflection coefficient versus geometrical parameter A2.

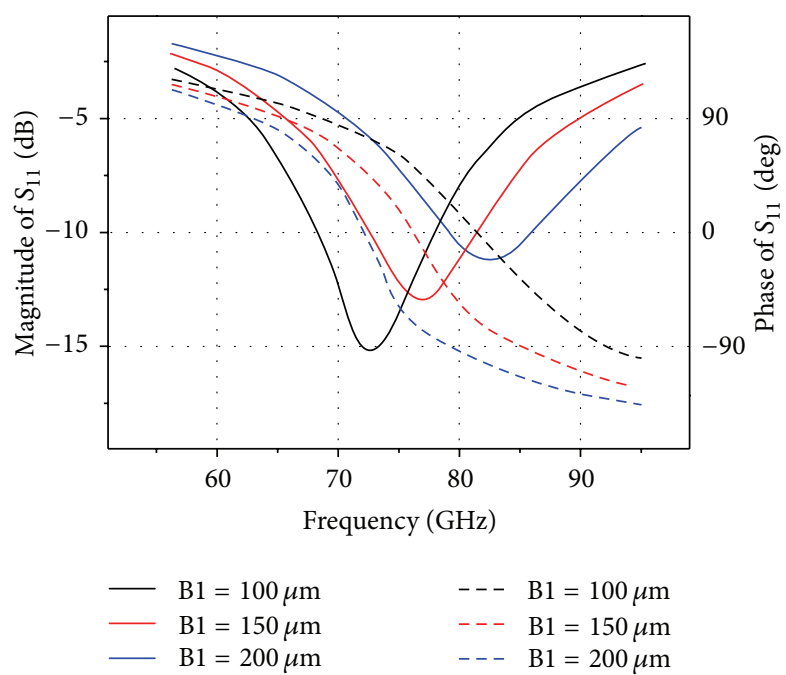

FIGURE 7: Magnitude and phase of reflection coefficient versus geometrical parameter B1.

and $\mathrm{B} 1$, less determined by geometrical parameters of A, B, and $\mathrm{B} 2$.

As we can see, the influence of the structure parameters on $S_{11}$ can be divided into three cases. For the magnitude of $S_{11}$, the cell size A and size B have similar influence. With increment of size $\mathrm{A}$ or $\mathrm{B}$, the AMC operation frequency increases. Conversely, with increment of length A1, A2, or $\mathrm{B} 1$, the AMC operation frequency decreases. For the phase of $S_{11}$, with increment of size A, A1, or A2, the center operating frequency of the AMC increases. Conversely, with increment of length $\mathrm{B}$ or $\mathrm{B} 1$, the center operating frequency of the AMC decreases. However, the variation of width B2 has little influence on $S_{11}$, both its magnitude and phase.

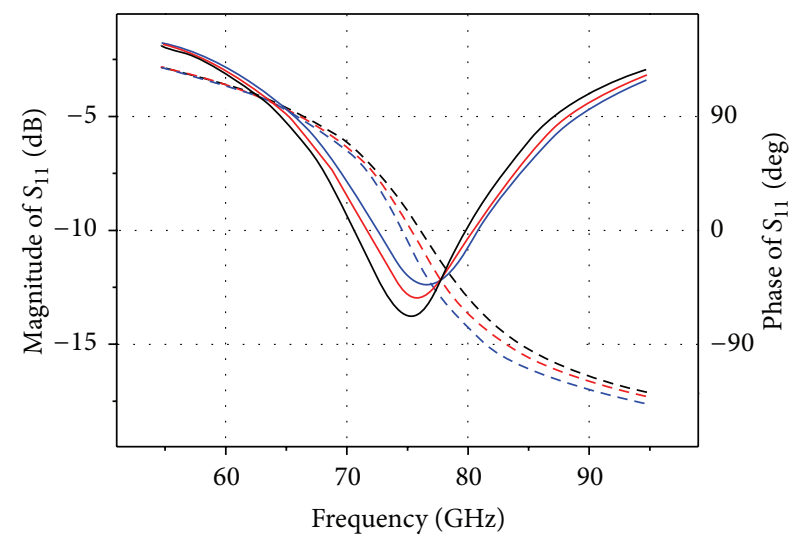

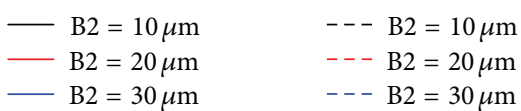

FIGURE 8: Magnitude and phase of reflection coefficient versus geometrical parameter B2.

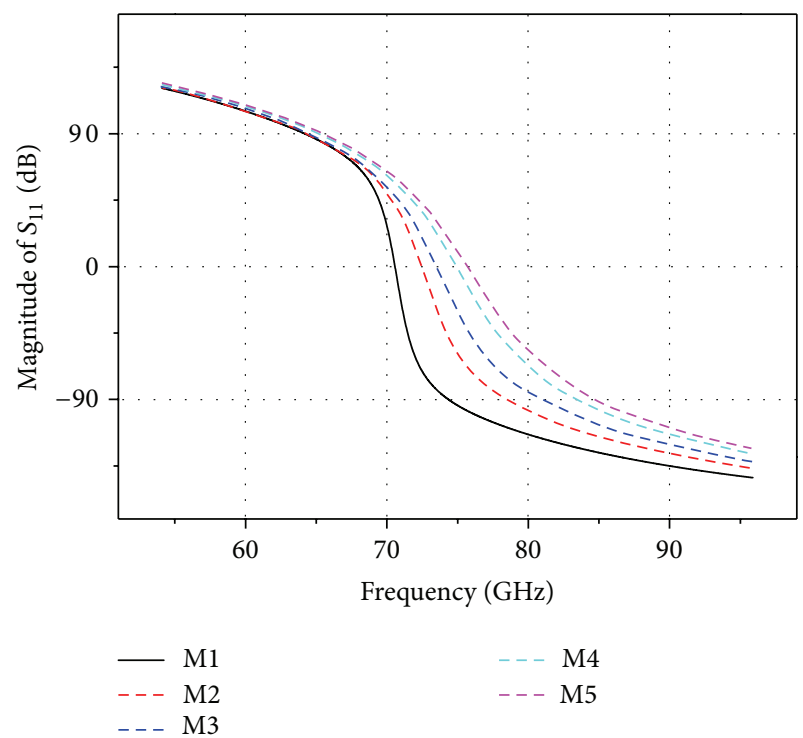

FIGURE 9: Variations of $S_{11}$ phase when the AMC is constructed in CMOS different metal layers (from M1 to M5).

\section{On Chip Dipole Antenna}

Figure 9 shows the phases of the reflection coefficient by implanting AMC into CMOS when its location is differed from M1 to M5. From the figure, it can be found that the AMC has the largest bandwidth when it is constructed in the M5 metal layer.

Figure 10 shows the configuration of a dipole antenna backed by the proposed AMC. The geometrical dimensions of the proposed AMC are shown in Figure 2. The dipole antenna is located on the top metal layer M6, while the AMC layer is located on M5. A metal ground plane is located on the bottom surface of the silicon substrate. The dipole length is $696 \mu \mathrm{m}$. 


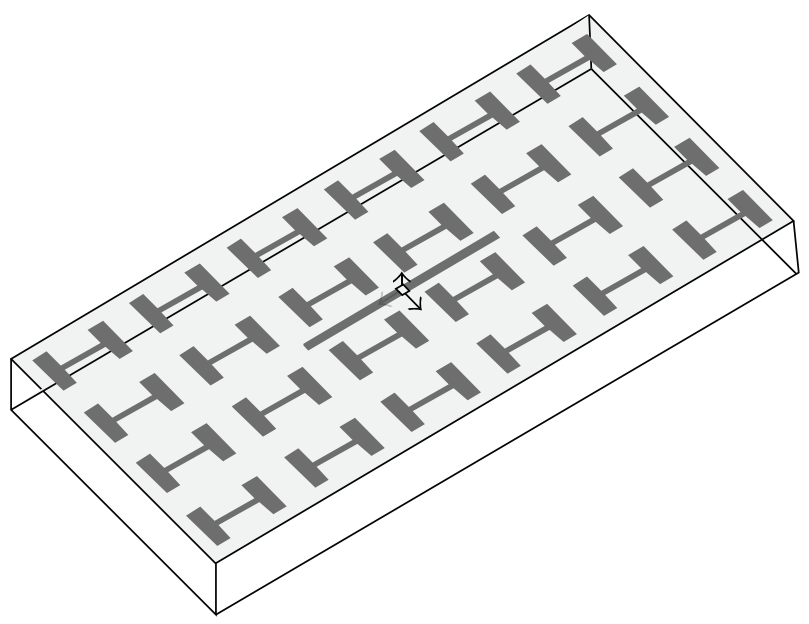

FIgURE 10: Dogbone shape AMC-backed dipole antenna.

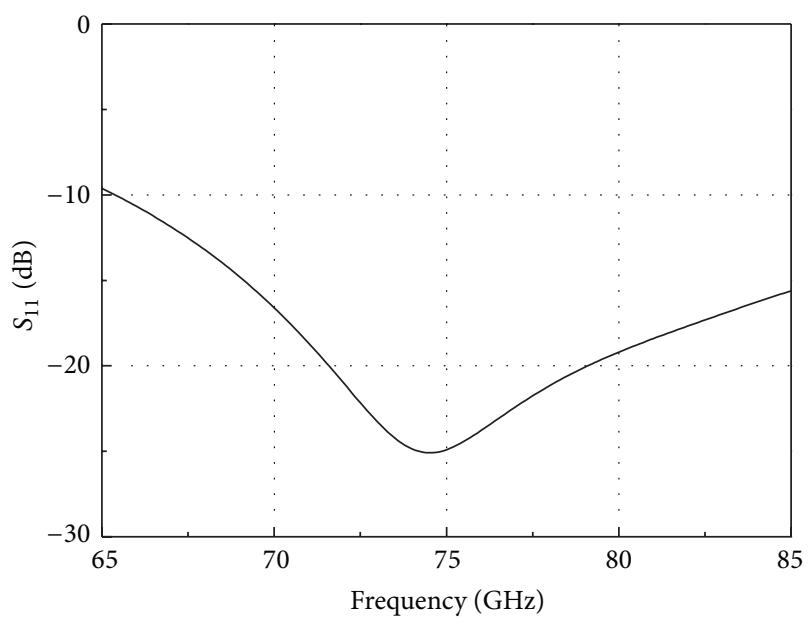

FIGURE 11: $S_{11}$ of the proposed antenna.

TABLE 1: Realized gains of the proposed antenna backed by AMC with different element numbers.

\begin{tabular}{lccc}
\hline & $4 * 6$ & $4 * 8$ & $6 * 6$ \\
\hline Gain $(75 \mathrm{GHz})$ & $0.72 \mathrm{dBi}$ & $-1.18 \mathrm{dBi}$ & $0.24 \mathrm{dBi}$ \\
\hline
\end{tabular}

The antenna input reflection coefficient is plotted in Figure 11. Its matched input impedance bandwidth $\left(S_{11}<\right.$ $-10 \mathrm{~dB}$ ) is more than $20 \mathrm{GHz}$. Radiation patterns of the proposed antenna at $75 \mathrm{GHz}$ are shown in Figure 12. Due to the perfect symmetry of the proposed antenna, its radiation patterns are symmetrical in both the $E$ and $H$ planes.

The proposed antennas whose AMC is constructed by different numbers of the dogbone shape element have been investigated. Their realized gains are listed in Table 1 when the dogbone shape array varies between $4 * 6,4 * 8$, and $6 * 6$.

\section{Conclusion}

Artificial magnetic conductor (AMC) constructed by twodimensional periodic dogbone shape element is applied in

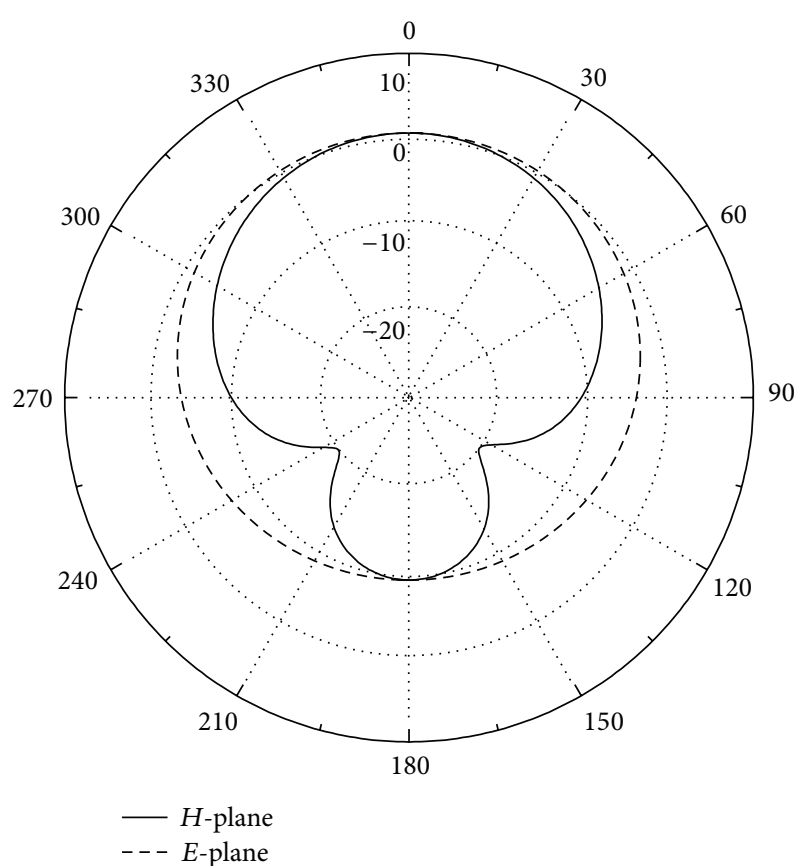

FIGURE 12: Radiation patterns of the proposed antenna.

millimeter-wave CMOS on chip dipole antenna design. The detailed frequency response of the proposed AMC has been completely studied. A gain of $0.72 \mathrm{dBi}$ is realized at $75 \mathrm{GHz}$ when the dipole antenna is backed by the proposed AMC with a $4 * 6$ dogbone shape array.

\section{Acknowledgments}

This work was supported in part by the National Basic Research Program of China under Contract 2010CB327403, the NSFC under Contract 61372020, the FANEDD under Contract 201045, the NCET under Contract 09-0910, and the ZJNSF under Contracts R1110003 and Y1110992.

\section{References}

[1] D. D. Falconer and J.-P. DeCruyenaere, "Coverage enhancement methods for LMDS," IEEE Communications Magazine, vol. 41, no. 7, pp. 86-92, 2003.

[2] G. D. Wang and S. Halajian, "Processing methods enhance collision-warning systems," Microwaves \& RF, vol. 36, no. 3, pp. 72-82, 1997.

[3] H. H. Meinel, "Applications of microwaves and millimeterwaves for vehicle communications and control in Europe," in Proceedings of the IEEE MTT-S International Microwave Symposium Digest, vol. 2, pp. 609-612, June 1992.

[4] C. O. McCaw, Remarks at G-7 Information Society Conference, Brussels, Belgium, 1995.

[5] M. Cotp, "Crash avoidance FLR sensors," Microwave Journal, pp. 122-126, 1994.

[6] E. O. Rausch, A. F. Peterson, and W. Wiebach, "Electronically scanned millimeter wave antenna using a Rotman lens," in Proceedings of the Radar Edinburgh International Conference, pp. 374-378, October 1997. 
[7] P. L. Lowbridge, "Low cost millimeter-wave radar systems for intelligent vehicle cruise control applications," Microwave Journal, vol. 38, no. 10, p. 7, 1995.

[8] S. T. Nicolson, A. Tomkins, K. W. Tang, A. Cathelin, D. Belot, and S. P. Voinigescu, "A $1.2 \mathrm{~V}, 140 \mathrm{GHz}$ receiver with on-die antenna in $65 \mathrm{~nm}$ CMOS," in Proceedings of the IEEE Radio Frequency Integrated Circuits Symposium (RFIC '08), pp. 229232, June 2008.

[9] H. Chu, Y. X. Guo, F. Lin, and X. Q. Shi, "Wideband $60 \mathrm{GHz}$ on-chip antenna with an artificial magnetic conductor," in Proceedings of the IEEE International Symposium on RadioFrequency Integration Technology (RFIT '09), pp. 307-310, Singapore, January 2009.

[10] F. Lin and B. L. Ooi, "Integrated millimeter-wave on-chip antenna design employing artificial magnetic conductor," in Proceedings of the IEEE International Symposium on RadioFrequency Integration Technology (RFIT '09), pp. 174-177, Singapore, January 2009.

[11] S. Pan, D. Wang, C. Guclu, and F. Capolino, "High impedance layer for CMOS on-chip antenna at millimeter waves," in Proceedings of the IEEE International Symposium on Antennas and Propagation (APSURSI '11), pp. 903-906, Spokane, Wash, USA, July 2011.

[12] P. Ying, M. A. Abdallah, and H. Zhirun, "A $60 \mathrm{GHz}$ on-chip antenna with meta-material structure," in Proceedings of the 28th National Radio Science Conference (NRSC '11), Cairo, Egypt, April 2011.

[13] G. Donzelli, A. Vallecchi, F. Capolino, and A. Schuchinsky, "Metamaterial made of paired planar conductors: particle resonances, phenomena and properties," Metamaterials, vol. 3, no. 1, pp. 10-27, 2009. 

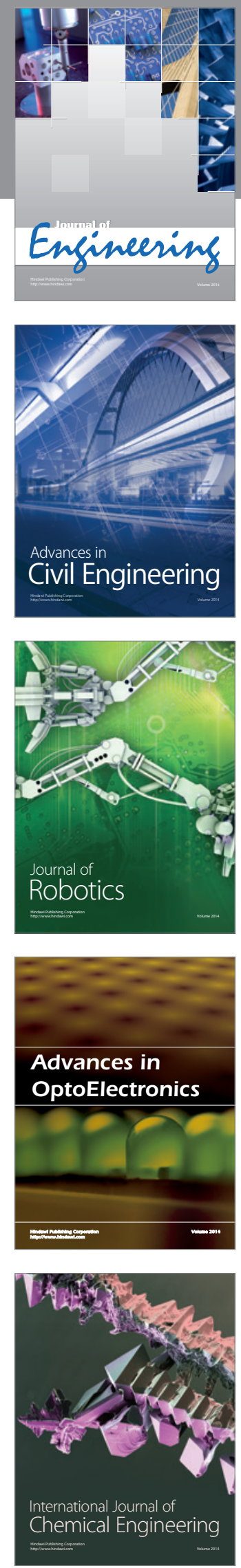

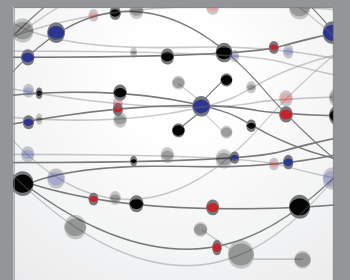

The Scientific World Journal
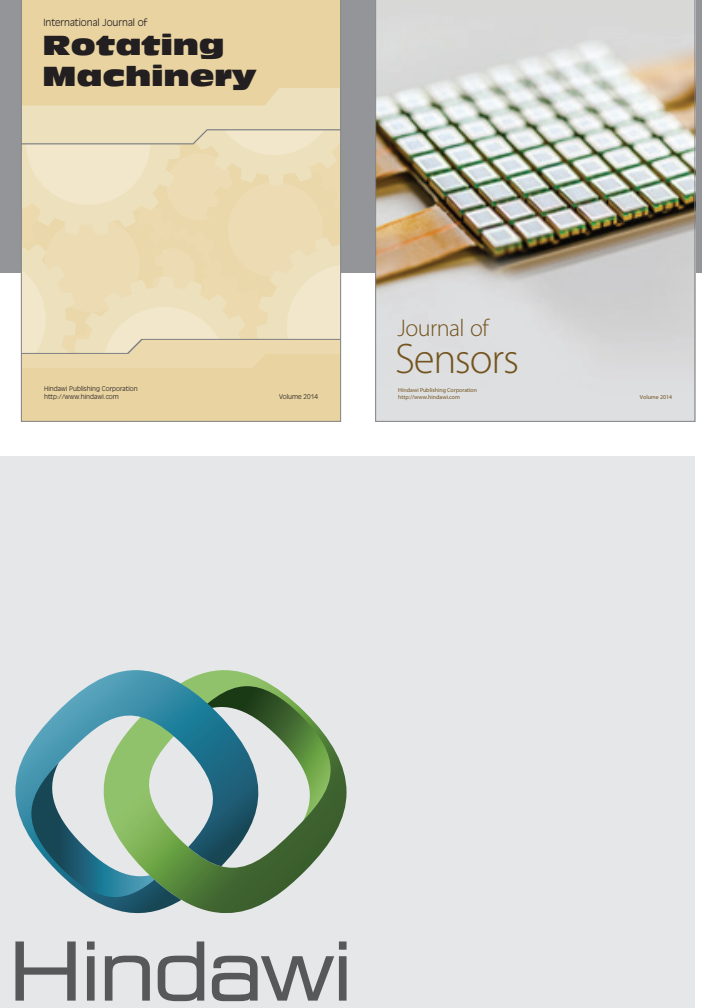

Submit your manuscripts at http://www.hindawi.com
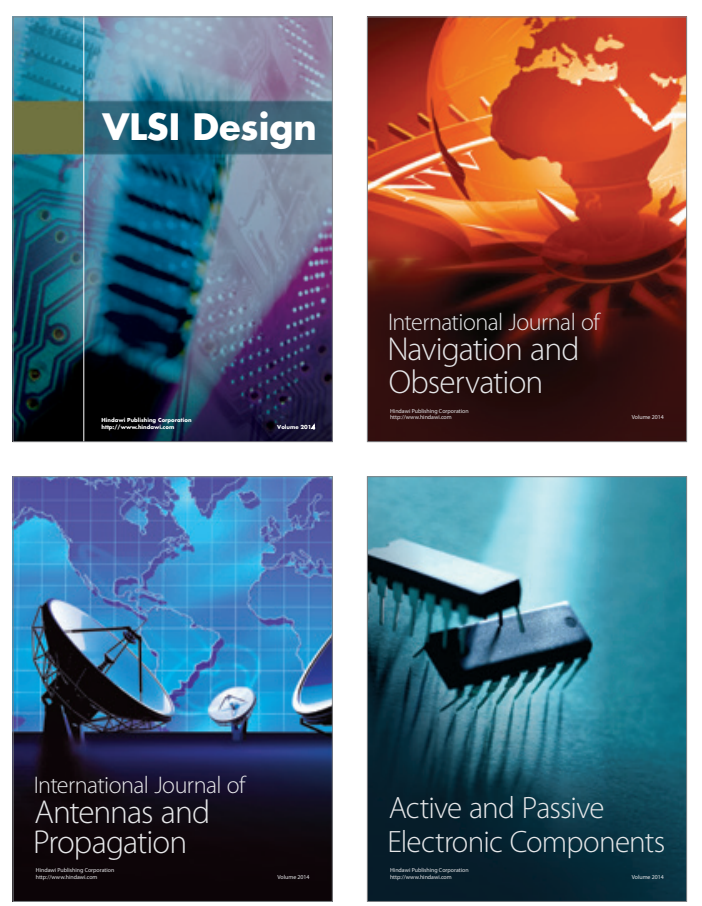
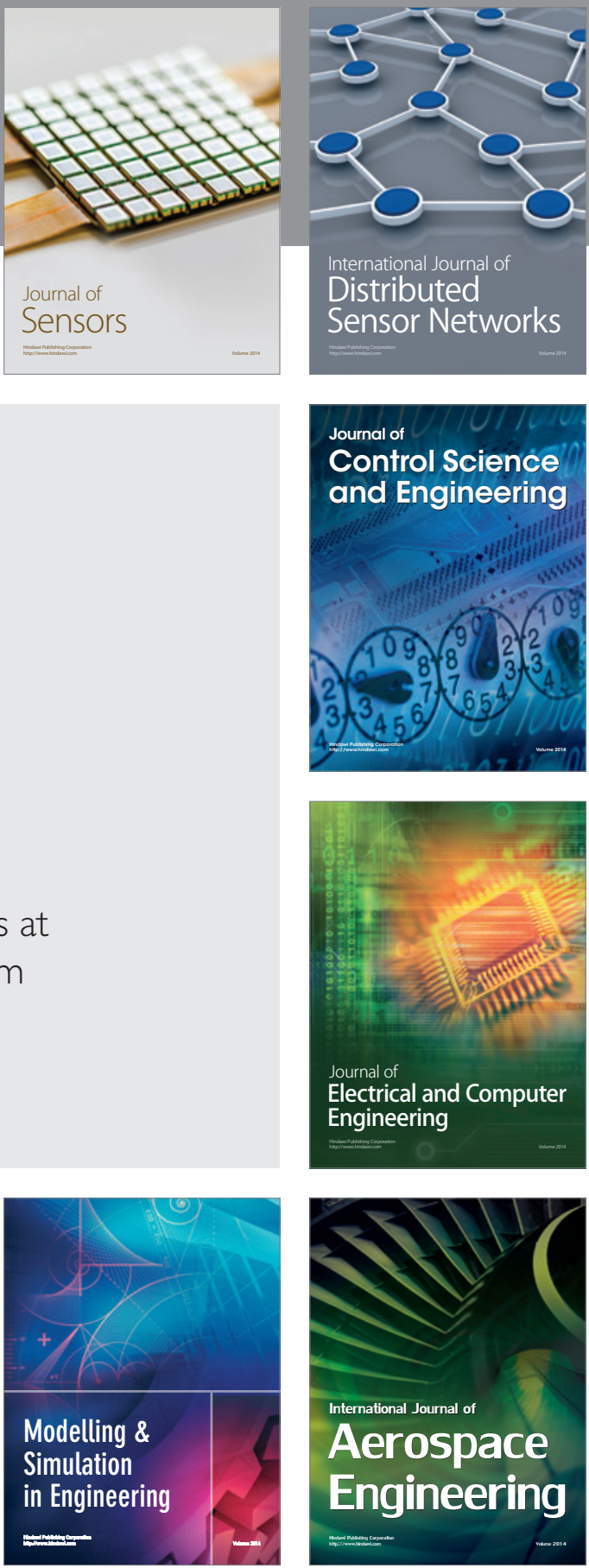

Journal of

Control Science

and Engineering
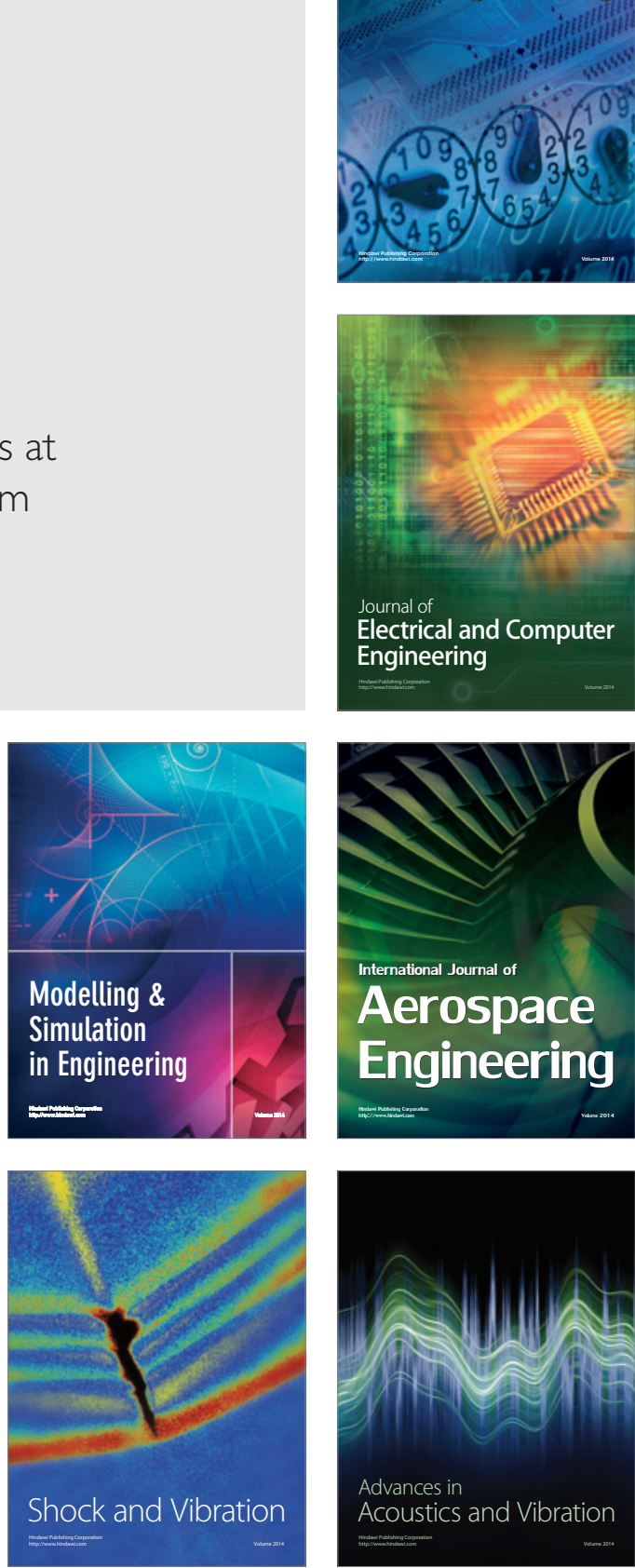